\title{
Study on the Performance of Carbon Dioxide Trans-Critical Refrigeration Cycle with Vortex Tube Expansion
}

\author{
Yefeng Liua, Ying Sun ${ }^{b}$ \\ University of Shanghai for Science \&Technology, School of Energy and Power Engineering, \\ Shanghai, 200093, China \\ ayfliu209@163.com, b1185445690@qq.com
}

\begin{abstract}
Keywords: Carbon dioxide; Trans-critical cycle; Vortex tube; COP
\end{abstract}
Abstract. In this paper, one carbon dioxide trans-critical refrigeration cycle with vortex tube expansion is proposed to replace traditional expansion valve in order to reduce the irreversible loss of the refrigeration system and improve its COP. The thermodynamic model of carbon dioxide trans-critical refrigeration system is built to simulate the effect of the vortex tube performance on the COP. The results show that the gas cooler outlet temperature and the discharge pressure have significant effects on the COP improvement of the vortex tube system. COP increases with the increase of the gas cooler outlet temperature and the decrease of the discharge pressure. When the gas cooler outlet temperature is $45^{\circ} \mathrm{C}$ and evaporation temperature is $0^{\circ} \mathrm{C}$, the COP increases $28 \%$ compared to traditional system with expansion valve. In addition, increasing the isentropic efficiency and the cold mass fraction of the vortex tube can also increase the COP by about $10 \%$.

\section{Introduction}

In recent years, the ever-increasing menace of ozone layer depletion and global warming has caused a great deal of attention from insiders to environmental protection and energy-saving refrigerants. The natural refrigerant $\mathrm{CO}_{2}$ which is a probable replacement for traditional refrigerants such as HCFCs (R22) or HFCs (R134a and R404A) is environmentally friendly (ODP=0, GWP=1), non-flammable and non-toxic. At a given saturation temperature and pressure, the surface tension, the liquid viscosity, and ratio of liquid to vapor density of $\mathrm{CO}_{2}$ are the lowest. It also has excellent heat transfer coefficients and compatibility with material of refrigeration system. As an environmentally friendly refrigerant that replaces traditional refrigerants, $\mathrm{CO}_{2}$ has been popularized in heat pump water heaters, automotive air conditioners, and heating application ${ }^{[1]}$. However, $\mathrm{CO}_{2}$ has a relatively high operating pressure due to its low critical temperature $\left(31.1^{\circ} \mathrm{C}\right)$ and high critical pressure $(7.38 \mathrm{MPa})$, a trans-critical cycle system is usually adopted. When the traditional expansion valve is used for isenthalpic expansion, the irreversible loss caused by the expansion valve is as high as $40 \%$ which is higher than that of the compressor ${ }^{[2]}$. Therefore, the $\mathrm{COP}$ of $\mathrm{CO}_{2}$ trans-critical refrigeration system is usually low, reducing cycle throttling loss becomes an important way to improve the $\mathrm{COP}$ of $\mathrm{CO}_{2}$ system.

The vortex tube is a mechanical device operating as a refrigerating machine without any moving parts, by using the Ranque-Hilsch effect to separate a compressed gas stream into a low total temperature region and a high one. In $2000, \mathrm{Li}^{[3]}$ first proposed the use of vortex tubes instead of throttle valves to reduce throttling losses. A certain thermodynamic analysis and calculation under the same working conditions to compare the irreversible loss of the throttle valve, the vortex tube and the turbine expander as the expansion device of $\mathrm{CO}_{2}$ trans-critical refrigeration cycle were performed by $\mathrm{He}^{[4]}$. Use of vortex tube as an expansion device in $\mathrm{CO}_{2}$ trans-critical cycle seems to be one of the promising cycle modifications to improve the system performance ${ }^{[5]}$.

Currently, most of the researches on vortex tube are generally about compressed air, there are few studies on refrigerants such as $\mathrm{CO}_{2}$ existing in gas-liquid phase transition, and they are not comprehensive enough ${ }^{[6-15]}$. The influence of the inlet temperature, pressure, the isentropic efficiency and cold mass fraction on the $\mathrm{COP}$ improvement of $\mathrm{CO}_{2}$ trans-critical cycle by using vortex tube 
instead of expansion valve is analyzed in this paper, which provides a theoretical basis for the design of the vortex tube and the optimization on the performance of $\mathrm{CO}_{2}$ trans-critical refrigeration cycle.

\section{$\mathrm{CO}_{2}$ Trans-critical Refrigeration Cycle with Vortex Tube Expansion}

$\mathrm{CO}_{2}$ Trans-critical Basic Refrigeration Cycle. In the $\mathrm{CO}_{2}$ trans-critical basic refrigeration cycle, a traditional expansion valve is taken usually, as shown in Fig.1. High pressure and high temperature $\mathrm{CO}_{2}$ gas is discharged from the compressor (state $2 \mathrm{~b}$ ), after no phase-change heat release process (state 3) via a gas cooler, $\mathrm{CO}_{2}$ enters the expansion valve and is expanded from the supercritical state to the two-phase state (state $3 \mathrm{~b}$ ), then it enters the evaporator to absorb heat. Finally, $\mathrm{CO}_{2}$ returns to the compressor.

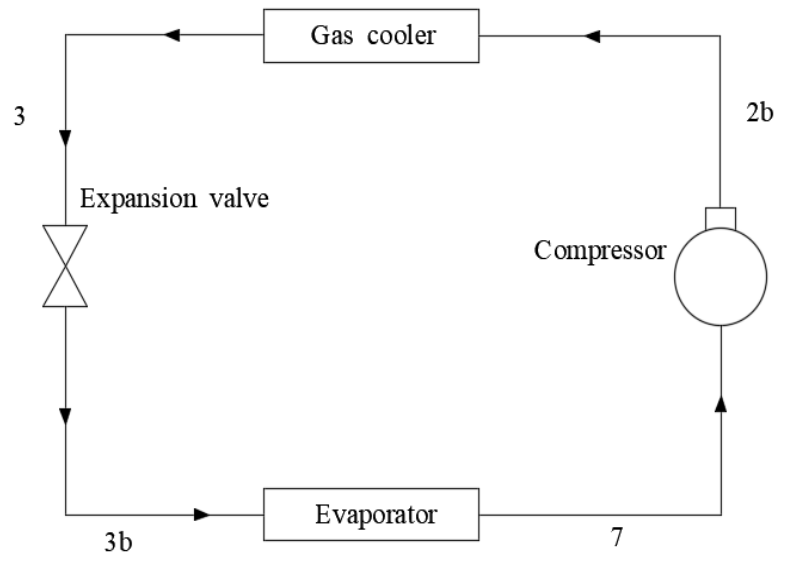

Fig.1. Schematic of $\mathrm{CO}_{2}$ trans-critical basic refrigeration cycle

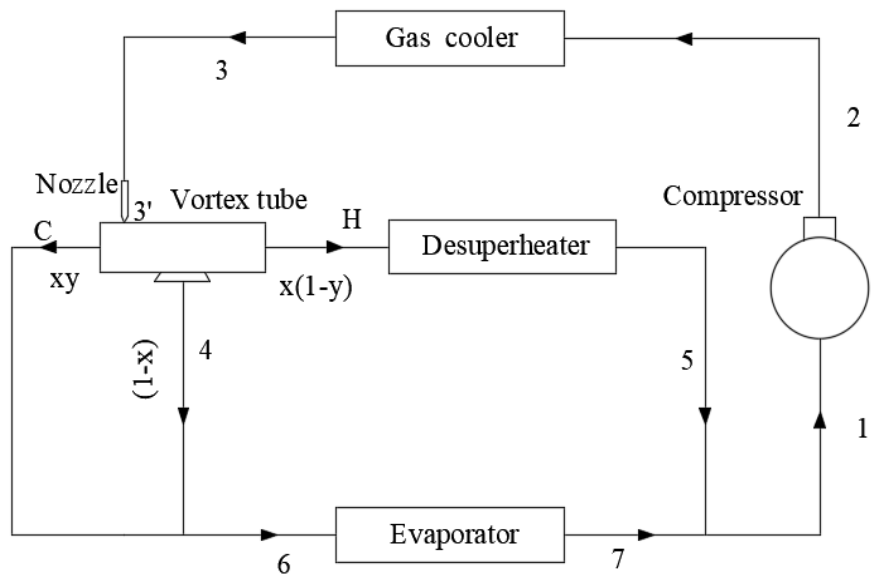

Fig.2. Schematic of $\mathrm{CO}_{2}$ trans-critical refrigeration cycle with vortex tube expansion

$\mathrm{CO}_{2}$ Trans-critical Refrigeration Cycle with Vortex Tube Expansion. The traditional vortex tube mainly contains the following parts: an inlet nozzle, a vortex chamber, a cold-end orifice, a hot end control valve and a tube. It converts a gas flow initially homogeneous in temperature, into two separate flows of differing temperatures. Due to the expansion of high pressure $\mathrm{CO}_{2}$ through the vortex tube nozzle into the two-phase (gas-liquid) region, the vortex tube designed in this paper has added a saturated liquid outlet compared to the traditional vortex tube, as shown in Fig.2. The gas is expanded from discharge pressure to evaporation pressure and divided into three fractions: saturated liquid (state 4), which is collected in a ring inside the vortex tube; saturated vapor (state C) and superheated gas (state $\mathrm{H}$ ), which are created because of the Ranque-Hilsch effect. The saturated liquid and vapor are mixed again (state 6) and going through the evaporator to give useful cooling effect. The superheated gas is cooled in the desuperheater to state 5 and mixed with the gas coming from the evaporator (state 7) before entering the compressor (state 1).

Two types of $\mathrm{CO}_{2}$ trans-critical refrigeration cycles are presented on the $\mathrm{p}-\mathrm{h}$ diagram, and each state point corresponds to the state point on Figs.1 and Figs.2. The cycle of the basic system is 7-2b-3-3b-7. It can be seen from Fig. 3 that the enthalpy of the outlet state point 3 'of the vortex tube nozzle after expansion is lower than that of the throttle outlet state point $3 \mathrm{~b}$, which is closer to the isentropic state point $3 \mathrm{~s}$. This is due to the higher isentropic effect of the vortex tube nozzle, which reduces the irreversible loss of the $\mathrm{CO}_{2}$ trans-critical refrigeration cycle system. At the same time, the superheated gas separated by the vortex tube is cooled by the desuperheater to further reduce the compressor inlet temperature and improve the system performance COP. 


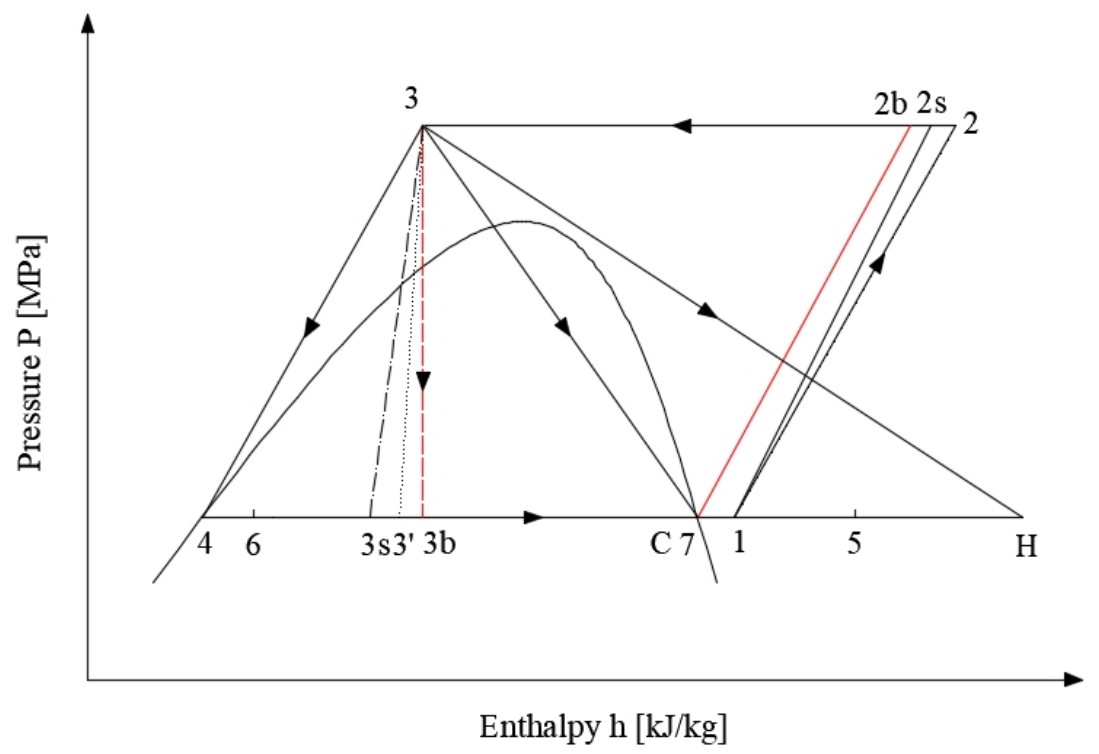

Fig.3. p-h diagram of $\mathrm{CO}_{2}$ trans-critical refrigeration cycle of the two systems

\section{Thermodynamic Analysis and Calculation of Two Systems}

Thermodynamic Calculations of $\mathrm{CO}_{2}$ Trans-critical Basic Refrigeration Cycle. According to Fig.3, the $\mathrm{COP}_{\mathrm{T}}$ formula for $\mathrm{CO}_{2}$ trans-critical basic refrigeration cycle system is as follows,

$$
\operatorname{COP}_{\mathrm{T}}=\frac{\left(\mathrm{h}_{7}-\mathrm{h}_{3 \mathrm{~b}}\right)}{\left(\mathrm{h}_{2 \mathrm{~b}}-\mathrm{h}_{7}\right)}
$$

The enthalpy at the vortex tube nozzle exit for given nozzle efficiency $\eta_{\mathrm{e}}$ can be calculated by,

$$
\mathrm{h}_{3^{\prime}}=\mathrm{h}_{3}-\eta_{\mathrm{e}}\left(\mathrm{h}_{3}-\mathrm{h}_{3 \mathrm{~s}}\right)
$$

Then the vapor quality is found $\mathrm{x}=\mathrm{x}\left(\mathrm{p}_{\mathrm{ev}}, \mathrm{h}_{3}\right.$ ) by using properties relation.

According to the definition of the cold mass fraction $y$, it can be calculated as the following,

$$
\mathrm{y}=\frac{\mathrm{m}_{\mathrm{c}}}{\mathrm{m}_{\mathrm{h}}+\mathrm{m}_{\mathrm{c}}}
$$

Assuming that all the liquid (1-x) is separated out from state 4 , the sum of mass flow rate of saturated vapor at state $\mathrm{C}$ and superheated gas at state $\mathrm{H}$, that is,

$$
\mathrm{m}_{\mathrm{h}}+\mathrm{m}_{\mathrm{c}}=\mathrm{x}
$$

Solving equations (3) and (4) can get the following results: mass fraction of saturated vapor is separated as cold fluid $\mathrm{m}_{\mathrm{c}}=\mathrm{xy}$, the rest absorbs all the kinetic energies and separated as hot fluid is $\mathrm{m}_{\mathrm{c}}=\mathrm{x}(1-\mathrm{y})$. Properties at state point $\mathrm{H}$ is given by,

$$
\mathrm{h}_{\mathrm{H}}[\mathrm{x}(1-\mathrm{y})]+\mathrm{xyh}_{\mathrm{C}}+(1-\mathrm{x}) \mathrm{h}_{4}=\mathrm{h}_{3}
$$

State point 6 is the mixing state point of state point 4 and state point $C$, the inlet enthalpy of evaporator $\mathrm{h}_{6}$ can be found by,

$$
\mathrm{h}_{6}(1-\mathrm{x}+\mathrm{xy})=(1-\mathrm{x}) \mathrm{h}_{4}+\mathrm{xyh}_{7}
$$

State point 1 is the mixing state of state point 5 and state point 7 , the inlet enthalpy of the compressor $h_{1}$ is calculated by,

$$
h_{1}=x(1-y) h_{5}+(1-x+x y) h_{7}
$$


As known compressor efficiency $\eta_{\mathrm{c}}$ and compressor discharge pressure $\mathrm{p}_{3}$, the outlet enthalpy of the compressor $h_{2}$ is found by,

$$
\mathrm{h}_{2}=\mathrm{h}_{1}+\eta_{\mathrm{c}}\left(\mathrm{h}_{2 \mathrm{~s}}-\mathrm{h}_{1}\right) \text {. }
$$

Based on the above calculations, the $\mathrm{COP}_{\mathrm{v}}$ of the vortex tube system is obtained by,

$$
\mathrm{COP}_{\mathrm{v}}=\frac{(1-\mathrm{x}+\mathrm{xy})\left(\mathrm{h}_{7}-\mathrm{h}_{6}\right)}{\mathrm{h}_{2}-\mathrm{h}_{1}}
$$

The improvement of COP is presented by $\triangle \mathrm{COP}$ as the following,

$$
\Delta \mathrm{COP}=\frac{\mathrm{COP}_{\mathrm{V}}}{\mathrm{COP}_{\mathrm{T}}}
$$

\section{Calculation Results and Analysis}

Assuming that the evaporation temperature is $0^{\circ} \mathrm{C}$, the compressor isentropic efficiency is 0.8 , the outlet temperature of the desuperheater is the same as the gas cooler outlet temperature. The influences of the gas cooler outlet temperature $T_{3}$, the isentropic efficiency of the vortex tube nozzle $\eta_{\mathrm{e}}$, the cold mass fraction $\mathrm{y}$ and the discharge pressure $\mathrm{P}_{3}$ on the system COP are analyzed. The variables setting is shown in Table 1.

Table 1 Thermodynamic cycle change parameter settings

\begin{tabular}{|c|c|c|c|c|}
\hline Variables & $\begin{array}{c}\text { Gas cooler outlet } \\
\text { temperature } \\
\mathrm{T}_{3}\left[{ }^{\circ} \mathrm{C}\right]\end{array}$ & $\begin{array}{c}\text { Vortex tube } \\
\text { isentropic } \\
\text { efficiency } \eta_{\mathrm{e}}\end{array}$ & $\begin{array}{c}\text { Cold mass } \\
\text { fraction y }\end{array}$ & $\begin{array}{c}\text { Discharge pressure } \\
\mathrm{P}_{3}[\mathrm{MPa}]\end{array}$ \\
\hline $\begin{array}{c}\text { Reference } \\
\text { value }\end{array}$ & 40 & 0.8 & 0.5 & 9 \\
\hline Range & $25-45$ & $0-1$ & $0.3-0.8$ & $8-12$ \\
\hline
\end{tabular}

Fig. 4 - Fig. 7 show the effects of the above variables on COPs of the two systems. In addition, the effects on COP improvement of the vortex tube expansion system compared with the valve expansion system are also displayed.

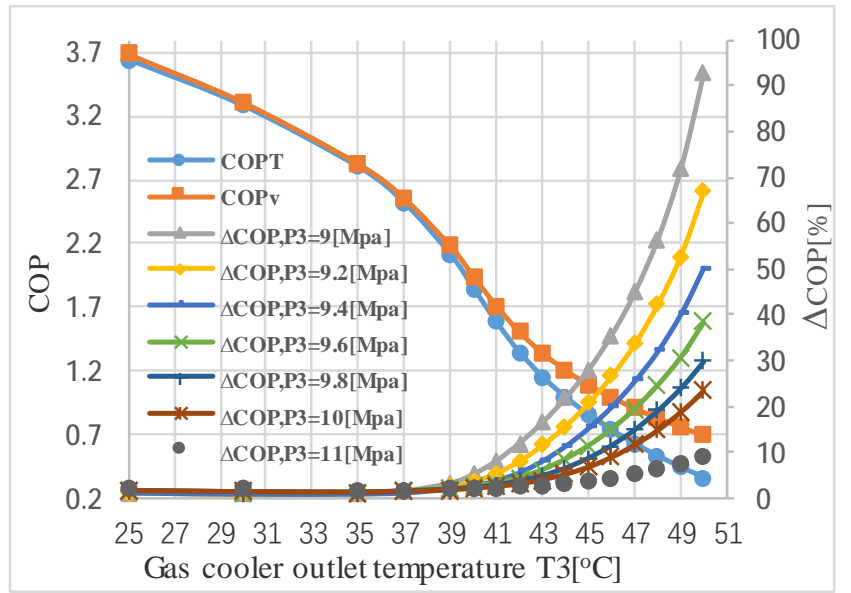

Fig.4. Variation of COP with gas cooler outlet temperature

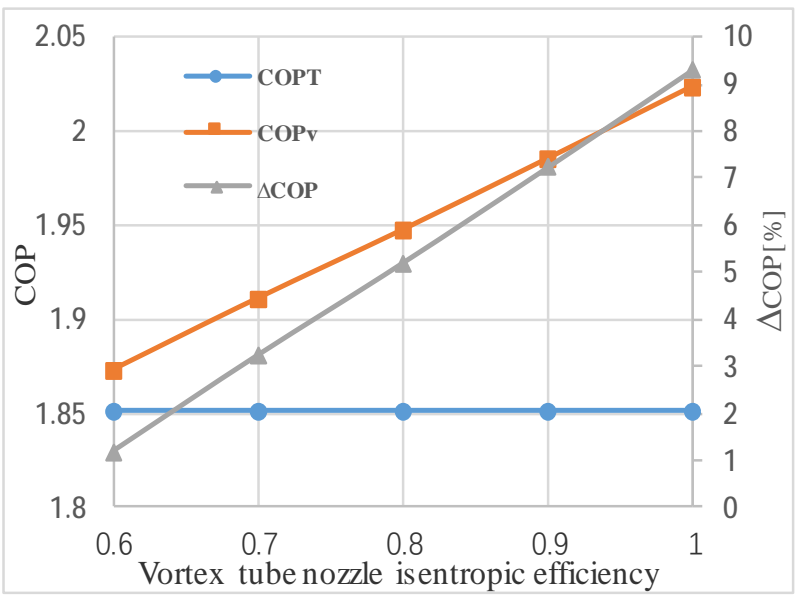

Fig.5. Variation of COP with vortex tube nozzle isentropic efficiency 
It can be seen from Fig. 4 that as the gas cooler outlet temperature increases, the COP of the both of the systems decreases. However, the $\triangle \mathrm{COP}$ increases with the increase of gas cooler outlet temperatures. Especially when the gas cooler outlet temperature is higher than $40^{\circ} \mathrm{C}$, the increases is significantly high. For example, if the discharge pressure is $9 \mathrm{MPa}$, when the temperature is $45^{\circ} \mathrm{C}$, the COP increases by $28 \%$. When the temperature is $47^{\circ} \mathrm{C}$, the COP increases by $45 \%$. Therefore, for the higher gas cooler outlet temperature and lower discharge pressure, the use of vortex tube is more effective in terms of higher COP improvement compared to basic cycle. The reason is that when the gas cooler outlet temperature is higher, the quality of the working fluid at the outlet of the vortex tube is higher which causes more efficient vortex tube energy separation, benefiting the COP improvement.

Fig. 5 shows that when the isentropic efficiency of the vortex tube nozzle increases, the system COP improvement can increase up to $9.3 \%$. The reason is that the increasing of isentropic efficiency can significantly reduce the irreversible loss of the expansion process and improve the COP.

Fig.6 shows the COP of the vortex tube system gradually increases with the increase of cold mass fraction $y$, and when $y=0.8$, the COP improvement increases by $12 \%$. The COP improvement $\triangle \mathrm{COP}$ increases due to the increase in heat rejection through the desuperheater.

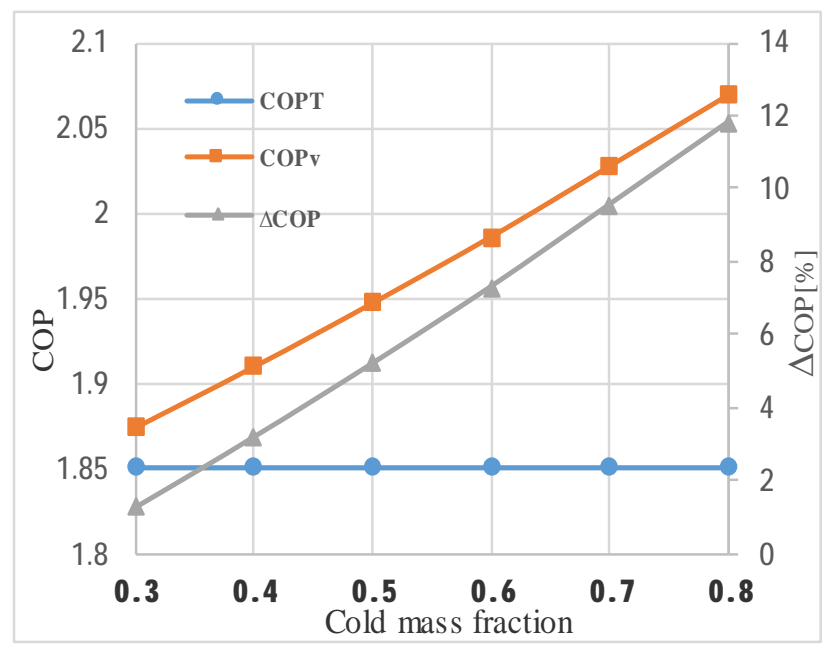

Fig.6. Variation of COP with cold mass fraction

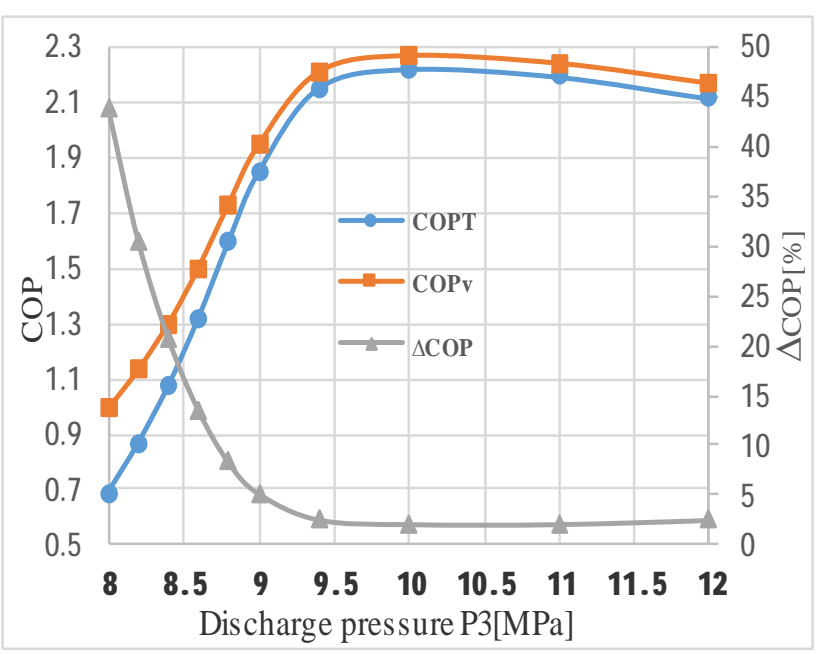

Fig.7.Variation of COP with discharge pressure

It can be seen from Fig.7 that the COP increases with the increase of discharge pressure ,but the $\triangle \mathrm{COP}$ decreases. For example, when the discharge pressure is $8.4 \mathrm{MPa}$, the $\triangle \mathrm{COP}$ increases by $21 \%$. When the discharge pressure is $9.0 \mathrm{MPa}$, the $\triangle \mathrm{COP}$ increases by $5 \%$. Especially when the gas cooler outlet pressure is lower than $10 \mathrm{MPa}$, the increases is significantly higher.

\section{Conclusion}

This paper proposes the use of vortex tube expansion instead of valve expansion to reduce irreversible losses and improve system performance $\mathrm{COP}$ in a $\mathrm{CO}_{2}$ trans-critical refrigeration cycle. The influence of various parameters on the $\mathrm{COP}$ is analyzed, the following conclusions are drawn.

(1) The higher the isentropic efficiency and the cold mass fraction of the vortex tube nozzle, the higher the COP improvement of the system, the increment can be up to $10 \%$.

(2) The effect of gas cooler outlet temperature and discharge pressure are more significant compared to the isentropic efficiency and the cold mass fraction of the vortex tube nozzle. The application of vortex tube is highly recommended when a higher outlet temperature and a lower discharge pressure is required. At $\mathrm{T}_{3}=45^{\circ} \mathrm{C}, \mathrm{P}_{3}=9 \mathrm{MPa}$, the COP increased by $28 \%$. 


\section{Acknowledgements}

This work was financially supported by Shanghai Pujiang Program (Project NO. 17PJ1407200)

\section{References}

[1] Sawalha S, Karampour M, Rogstam J. Field Measurements of Supermarket Refrigeration Systems. Part I: Analysis of $\mathrm{CO}_{2}$ trans-critical refrigeration systems. Applied Thermal Engineering, 2015, 87:633-647.

[2] Robinson DM, Groll EA. Efficiencies of $\mathrm{CO}_{2}$ Trans-Critical Cycles with and without an Expansion Turbine. International Journal of Refrigeration, 1998 (21):577-89.

[3] Li D, Back JS. D. Li, J.S. Baek, E.A. Groll, et al. Thermodynamic Analysis of Vortex Tube and Work Output Expansion Devices for the Trans-Critical Carbon Dioxide Cycle. Fourth IIR-Gustav Lorentzen Conference on Natural Working Fluids at Purdue, Purdue University, USA, 2000: 433-440.

[4] He Y, Hou Y, Zhao H, et al. A Comparative Study on Irreversible Loss of Three Kinds of Expansion Devices. Cryogenics \& Superconductivity, 2005, 33(2):53-57.

[5] Groll E, Jun-HyeungKim. Review Article: Review of Recent Advances Toward Trans-critical $\mathrm{CO}_{2}$ Cycle Technology. Hvac \& R Research, 2007, 13(3):499-520.

[6] Han X, Li N, Wu K, et al. The Influence of working Gas Characteristics on Energy Separation of Vortex Tube. Applied Thermal Engineering, 2013, 61(2):171-177.

[7] Manimaran R, Lund H, Kaiser M J. Computational Analysis of Energy Separation in a Counter-Flow Vortex Tube Based on Inlet Shape and Aspect Ratio. Energy, 2016, 107:17-28.

[8] Shamsoddini R, Khorasani A F. A New Approach to Study and Optimize Cooling Performance of a Ranque-Hilsch Vortex Tube. International Journal of Refrigeration, 2012, 35(8):2339-2348.

[9] Kandil HA, Abdelghany ST. Computational Investigation of Different Effects on the Performance of the Ranque-Hilsch Vortex Tube. Energy, 2015(84): 207-218.

[10] Chen J, Zeng R, Zhang W, et al. Numerical Analysis of Energy Separation in Ranque-Hilsch Vortex Tube with Gaseous Hydrogen Using Real Gas Model. Applied Thermal Engineering, 2018.

[11] Yamaguchi H, Zhang X R. A Novel $\mathrm{CO}_{2}$ Refrigeration System Achieved by $\mathrm{CO}_{2}$ Solid-Gas Two-Phase Fluid and Its Basic Study on System Performance. International Journal of Refrigeration, 2009, 32(7):1683-1693.

[12] S J B, Smolka J, Banasiak K, et al. Performance Improvement of the R744 Two-Phase Ejector with an Implemented Suction Nozzle Bypass. International Journal of Refrigeration, 2018.

[13] Chang S W, Yu K C. Thermal Performance of Reciprocating Two-Phase Thermo-syphon with Nozzle. International Journal of Thermal Sciences, 2018, 129:14-28.

[14] Sawalha S, Piscopiello S, Karampour M, et al. Field Measurements of Supermarket Refrigeration Systems. Part II: Analysis of HFC refrigeration systems and comparison to $\mathrm{CO}_{2}$ trans-critical. Applied Thermal Engineering, 2017, 111:170-182.

[15] Sarkar J. Cycle Parameter Optimization of Vortex Tube Expansion Trans-Critical $\mathrm{CO}_{2}$ System. International Journal of Thermal Sciences, 2009, 48(9):1823-1828. 